LBNL-Xxxx

\title{
Safer Vehicles for People and the Planet
}

Published in American Scientist, 96:2 (March-April), 122-128

Tom Wenzel

Lawrence Berkeley National Laboratory

1 Cyclotron Road

Berkeley, CA 94720

Marc Ross

Physics Department

University of Michigan

Ann Arbor, MI 48109

This work was supported by The Energy Foundation and The William and Flora Hewlett Foundation. Prepared for the U.S. Department of Energy under Contract No. DE-AC02$05 \mathrm{CH} 11231$. 


\section{DISCLAIMER}

This document was prepared as an account of work sponsored by the United States Government. While this document is believed to contain correct information, neither the United States Government nor any agency thereof, nor The Regents of the University of California, nor any of their employees, makes any warranty, express or implied, or assumes any legal responsibility for the accuracy, completeness, or usefulness of any information, apparatus, product, or process disclosed, or represents that its use would not infringe privately owned rights. Reference herein to any specific commercial product, process, or service by its trade name, trademark, manufacturer, or otherwise, does not necessarily constitute or imply its endorsement, recommendation, or favoring by the United States Government or any agency thereof, or The Regents of the University of California. The views and opinions of authors expressed herein do not necessarily state or reflect those of the United States Government or any agency thereof, or The Regents of the University of California.

Ernest Orlando Lawrence Berkeley National Laboratory is an equal opportunity employer. 


\begin{abstract}
Motor vehicles contribute to climate change and petroleum dependence. Improving their fuel economy by making them lighter need not compromise safety
\end{abstract}




\section{Introduction}

The cars and trucks plying America's roads and highways generate roughly 20 percent of the nation's total emissions of carbon dioxide, a pollutant that is, of course, of increasing concern because of its influence on climate. Motor vehicles also account for most of our country's dependence on imported petroleum, the price of which has recently skyrocketed to near-record levels. So policymakers would welcome the many benefits that would accrue from lessening the amount of fuel consumed in this way. Yet lawmakers have not significantly tightened new vehicle fuel-economy standards since they were first enacted three decades ago. Since then, manufacturers have, for the most part, used advances in automotive technology, ones that could have diminished fuel consumption, to boost performance and increase vehicle weight. In addition, the growth in popularity of pickups, sport utility vehicles (SUVs) and minivans - and the large amounts of gas they typically guzzle - has resulted in the average vehicle using the same amount of fuel per mile as it did 20 years ago.

One of the historical impediments to imposing tougher fuel-economy standards has been the long-standing worry that reducing the mass of a car or truck to help meet these requirements would make it more dangerous to its occupants in a crash. People often justify this concern in terms of "simple physics," noting, for example, that, all else being equal, in a head-on collision, the lighter vehicle is the more strongly decelerated, an argument that continues to sway regulators, legislators and many in the general public.

We have spent the past several years examining the research underlying this position-and some recent work challenging it. We have also conducted our own analyses and come to the conclusion that the claim that lighter vehicles are inherently dangerous to those riding in them is flawed. For starters, all else is never equal; other aspects of vehicle design appear to control what really happens in a crash, as reflected in the safety record of different kinds of vehicles. What's more, the use of high-strength steel, light-weight metals such as aluminum and magnesium, and fiber-reinforced plastics now offers automotive engineers the means to fashion vehicles that are simultaneously safer and less massive than their predecessors, and such designs would, of course, enjoy the better fuel economy that shedding pounds brings.

\section{Saving Gas, Saving Lives}

If a typical car could somehow drop 10 percent of its mass, its fuel economy would increase by anywhere from 3 percent to 8 percent. (The larger value applies if the size of the engine is also reduced to keep acceleration performance the same.) Designers are keenly aware of this relation, and after federal fuel-economy standards were first enacted, automakers virtually eliminated the heaviest cars (those weighing more than 4,000 pounds) from their new-vehicle fleets. These behemoths went from 46 percent of sales in 1975 to just 9 percent in 1980, after which only a dwindling number could be found in showrooms (Figure 1). But in the late 1980s, the sales of heavier "light trucks," including many of the SUVs used as substitutes for cars, began to increase. By 2003, the fraction of light trucks weighing more than 4,000 pounds reached 32 percent. 
Figure 1. To meet fuel-economy standards put in place in during the 1970s, manufacturers reduced the number of heavy cars they sold, in particular those weight more than 4,500 pounds (dark blue), which by 1980 became comparatively rare items in showrooms. But in later decades, lessened concerns about fuel prices and lax fuel-economy standards for light trucks led to burgeoning sales of pickups and SUVs in this weight class (red), which in 2006 accounted for almost 40 percent of the new-vehicle fleet. (source: Heavenrich 2005)

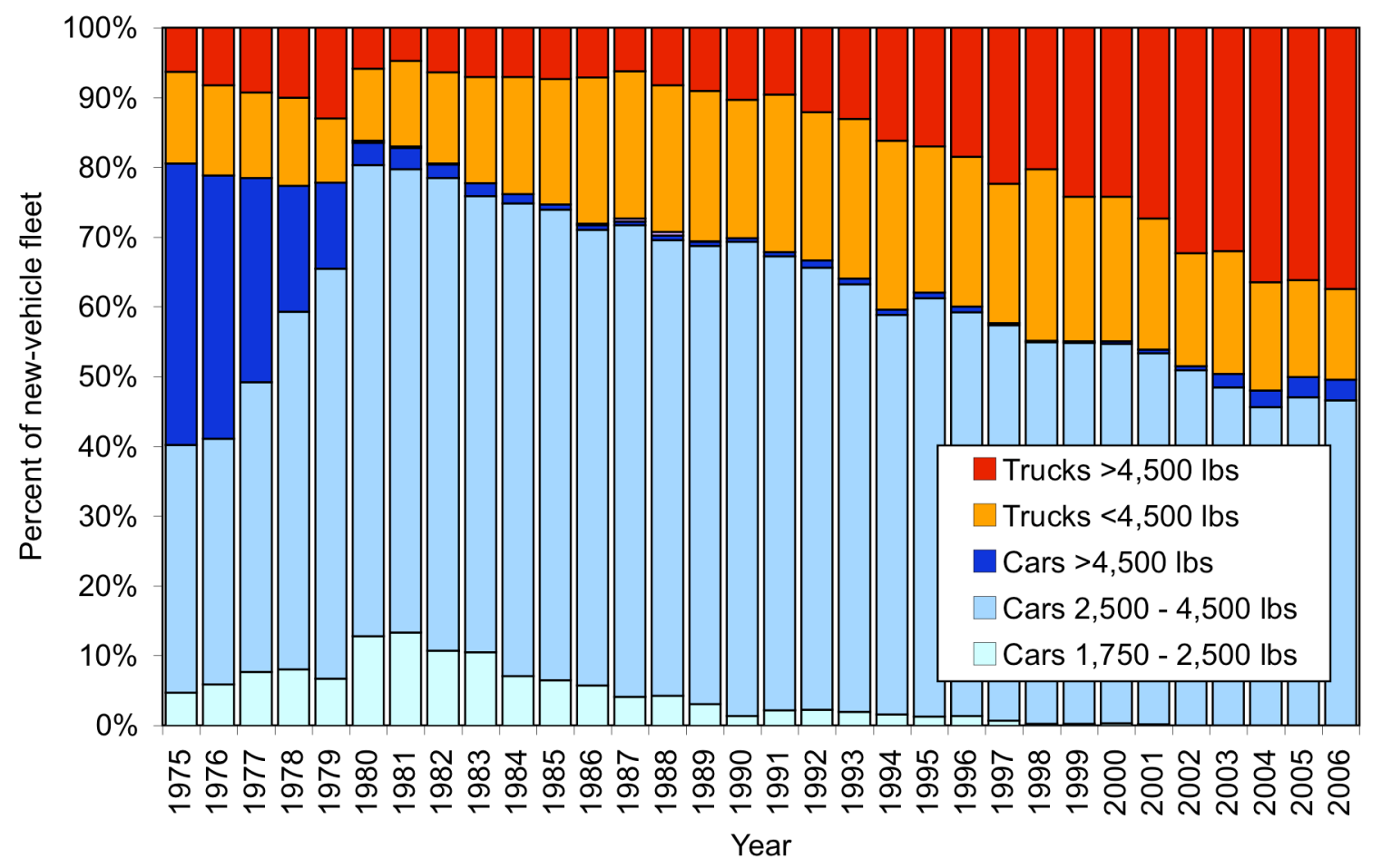

People often feel very secure and protected when driving such mammoth vehicles. And indeed, the tendency of such large masses to resist sudden deceleration adds some degree of safety. But deceleration is a relatively small danger compared with the three phenomena that most frequently kill and maim people in a serious crash: intrusion of another vehicle or roadside object into the passenger compartment, rollovers, or failure of the restraints to keep the occupants from hitting hard interior surfaces.

The key factors that determine whether a life-threatening intrusion will take place are the strength of the passenger compartment and the height and stiffness of the collision partner. Automakers could thus use stronger materials and more compatible designs to reduce casualties in two-vehicle collisions; adding mass is not necessary. For example, designers could incorporate light honeycomb-sandwich panels or fiber-reinforced materials to help sever the connection between mass and strength.

The best strategies for avoiding rollover are to lower a vehicle's center of gravity and to increase its track width (the distance between the right and left tires). Electronic stability control, a relatively new technology, also helps by providing automatic braking separately at the four wheels in such a way as to inhibit rollover. Once such a mishap occurs, the crush resistance of the roof normally determines whether seat-belted occupants get hurt. And, of course, whether you are belted in will affect whether you end up being ejected during a crash, which would likely result in serious or fatal injury. 
Restraints, both safety belts and air bags, and interior padding provide important protection to occupants in rollovers - indeed, they serve this critical function in all types of crashes. Sidecurtain air bags, which reduce head contact with windows, are becoming more common, and advanced seat belts, ones with pretensioners and load limiters, are also being incorporated in many models. Under research are four-point seat belts, which hold occupants in position in sideimpact crashes better than do today's three-point, lap-and-shoulder belts.

Electronic stability control, side-curtain airbags and advanced seat belts tend to be included in heavier, more-expensive, vehicles. But such cutting-edge safety equipment need not add much mass, particularly if attention is paid to this goal. And although lighter vehicles are often at a disadvantage in crashes with heavier ones, a general reduction in vehicle weight across all vehicle types would not compromise safety, in part because the relative masses of colliding vehicles wouldn't change, but also because a substantial majority of casualties in motor vehicle crashes are unrelated to the masses of the vehicles involved.

Just what then does control safety on the road? Driver behavior and environmental factors contribute most to whether a serious accident takes place and to the speed of the impact. Whether the occupants of the car or truck involved are properly wearing their safety belts influences the type and extent of injuries, as do the age and physical condition of these people. But it is vehicle design that above all affects the severity of the consequences of a given crash.

\section{Nothing Simple About Safety}

Although serious auto wrecks are relatively rare events, the consequences are momentous enough that many consumers study the safety characteristics of the different vehicles they are contemplating for purchase. Buyers often consider the protective equipment offered and scrutinize the results of crash tests when deciding which model to choose. Such information is widely available. The National Highway Traffic Safety Administration regularly conducts crash tests and rates vehicle models under its New Car Assessment Program. The Insurance Institute for Highway Safety also performs such tests and publicizes the results in various ways, including on its Web site. Consumer Reports publishes a Safety Assessment rating, which is a combination of the NHTSA's findings and results of handling and braking tests conducted by that magazine's parent organization, Consumers Union.

As important as these studies are, one must accept that they have limited value. After all, no test procedure can replicate all of the conditions that come into play when things go wrong on the road. To address this rather fundamental shortcoming, we and other investigators have sifted through a great deal of real-world data to better reveal how driver and environmental conditions influence crashes - and how well safety devices and vehicle design protect occupants when an accident happens. The yardstick we and others use for this purpose takes the form of the fatality or serious-injury rate for various vehicle types or for specific makes and models. Unfortunately, in these kinds of analyses it is difficult, often impossible, to judge the relative contributions of driver behavior, environmental conditions and vehicle attributes to the overall fatality or injury rate. 
For our studies, we calculated the risk of driver fatality using the Fatality Analysis Reporting System, or FARS, the federal database of all deaths stemming from accidents on public roadways. "Fatality risk," in our formulation, is simply the number of driver deaths divided by the number of registered vehicles operating during the year under examination. Actually, our procedure is a little more complicated, because we typically analyze a range of several years and because we normally do not have registration records for the entire period (the full complement of these data being too costly to obtain). So we estimate the total number of registered-vehicle years indirectly by making some straightforward deductions from the information contained in our limited records (such as the model year of each registered vehicle). Using this approach, we can easily calculate fatality risk for a particular type of vehicle or for an individual make or model.

Researchers at the Insurance Institute for Highway Safety, as well as some others, use this same risk metric for many of their studies. We were, however, interested in exploring not only the danger to someone operating a particular type or model, but also the risk that such a vehicle imposes on other drivers. That is, we were keen to find out the total burden society bears by encouraging one sort of motor vehicle over another. Usually investigators only present and discuss the risk to occupants of the car or truck in question - as if society at large has no stake in the mayhem caused by some vehicles as long as those riding in them aren't themselves killed.

Because we used actual crash statistics, the values we calculated reflect the risk of involvement in a crash and the speed at which it occurs, which hinge primarily on environmental factors and the behavior of the driver, as well as the risk of fatality once a serious crash has taken place, which depends on belt use, vehicle design and driver frailty. As such, our use of the word "risk" here is just shorthand for "risk as a car or truck is really driven."

One of the most important things we found in our studies is that drivers are just as safe in cars as they are in SUVs and pickups (Figure 2). This result is easily explained: Although the risk of dying in a collision is often lower in SUVs and pickups, their high center of gravity makes them more susceptible to rollovers. Thankfully, the recent trend of manufacturers to produce so-called crossover SUVs, which are lower and sometimes wider than conventional truck-based SUVs, has led to large reductions in the rollover risk. 
Figure 2. Driving is, of course, dangerous-but just how dangerous depends a great deal on the type of vehicle people choose to do it in. Large pickup trucks, for example, are more than five times more likely to cause a fatality than are imported luxury cars. And a larger fraction of the fatality risk from such trucks falls on the drivers of other vehicles. But driver behavior is also a factor, one that probably accounts for why minivans prove much safer than sports cars. (Differences in risk of less than 10 percent are not statistically significant.)

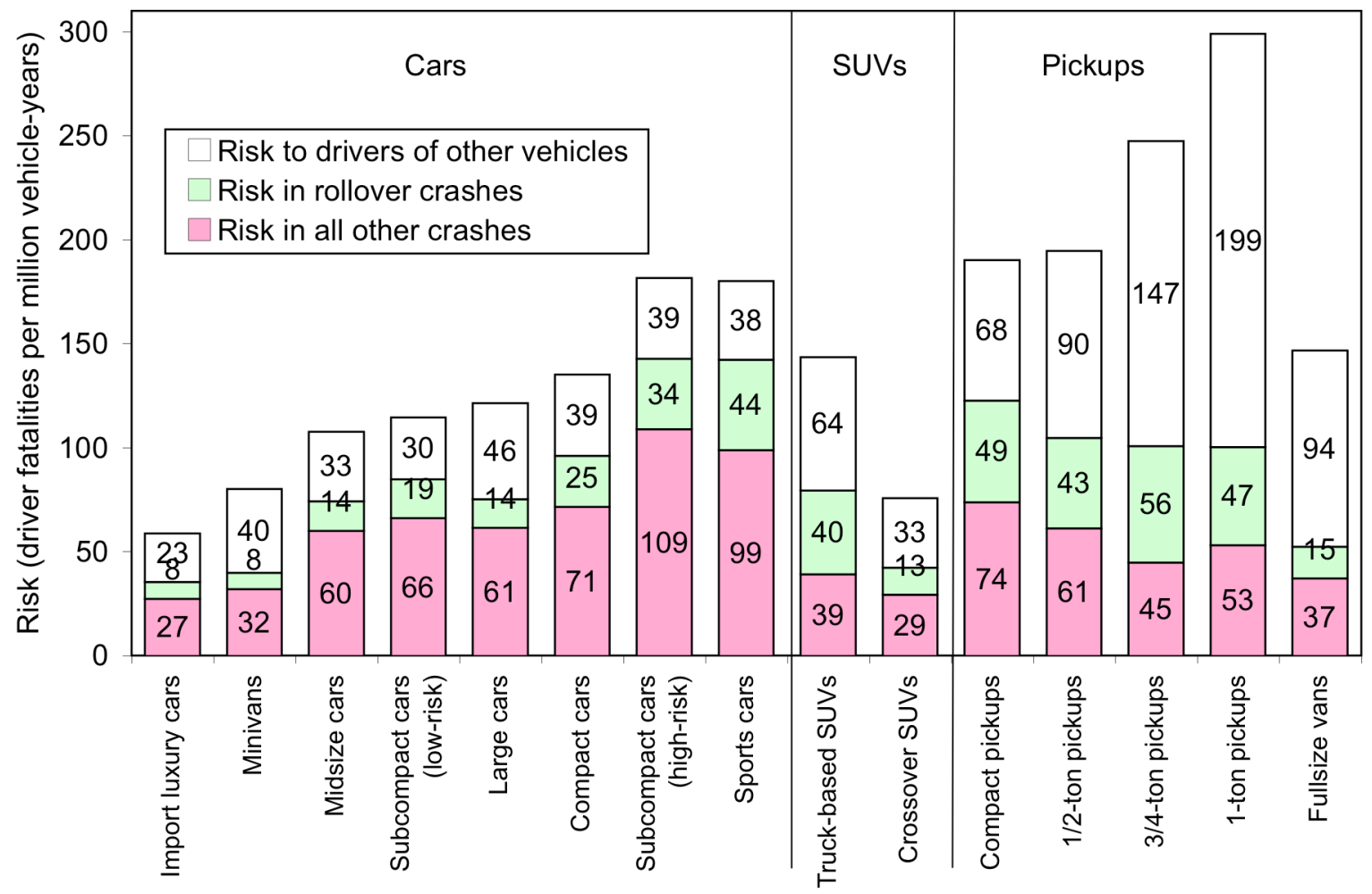

Among cars, large ones present only slightly lower risks than midsize models, compact cars or even the safer subcompacts. The small differences are within the statistical uncertainty of the analysis. What really surprised us, however, was the wide range in risk among different models of subcompact cars - the worst ones having an average fatality risk that is three times that of the best ones.

It is not hard to find examples of a small car, a large car and an SUV that all pose about the same amount of risk to their drivers. On the other hand, in terms of the risk to drivers of other vehicles, SUVs and pickups are much more dangerous than cars or minivans. Common sense explains why: Most conventional SUVs are merely carlike cabins bolted onto the frames of pickup trucks, which include two longitudinal steel beams that can act like spears or fork tines when striking a car, often overriding a bumper in a frontal crash or punching through a door in a side impact (Figure 3). These high, rigid structures make the designs of pickup trucks and truck-based SUVs fundamentally incompatible with those of cars, which is why researchers in the field of traffic safety refer to the "aggressivity" of such designs. 
Figure 3. Unlike most cars, pickup trucks and truck-based SUVs are built on a frame that contains two longitudinal steel rails, which often prove to be very "aggressive" in accidents with other vehicles. The frame shown here is used in Dodge's Ram 150 pickup truck.

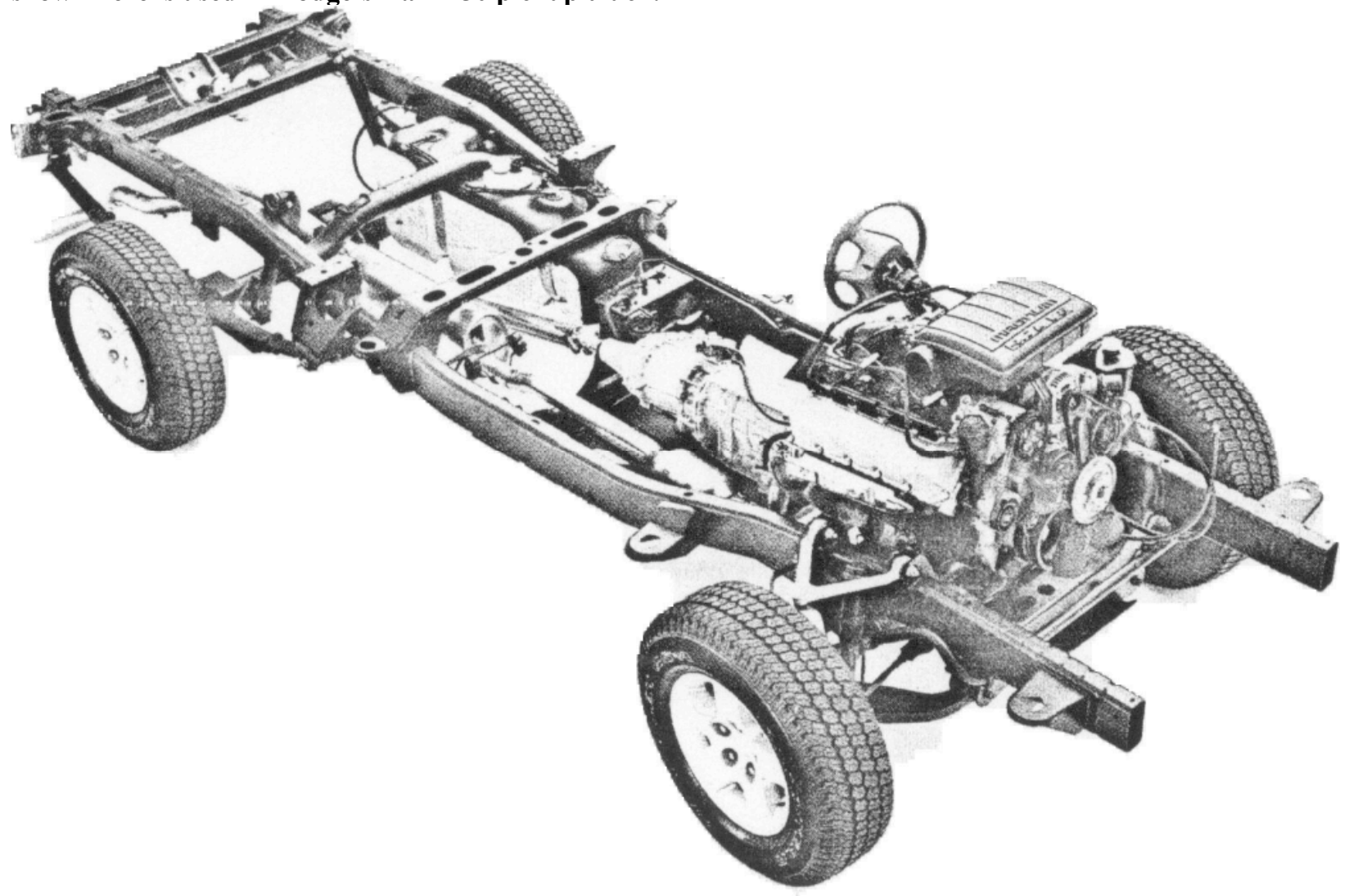

These experts have considered various ways to reduce the aggressivity of SUVs and light trucks towards cars. Strategies include redesigning truck fronts and bumpers to make them lower or "softer", and raising the door sills of cars to prevent the intrusion of truck bumpers and frame rails. Our analysis of car-based crossover SUVs that lack rigid frame rails and have lower fronts indicates that these newer designs are much less dangerous than truck-based SUVs (they also provide roughly 3- to 4-miles-per-gallon better fuel economy for a given interior volume).

We also found, not surprisingly, that the aggressivity of pickup trucks increases with their rated carrying capacity. The largest pickups are nearly six times more aggressive to other vehicles than the average car. Indeed, our study uncovered a shocking statistic: We calculate that during the 14 years the average one-ton pickup truck is driven, it has almost a 1 percent chance of killing someone. (Only one-third of this huge risk falls on those driving the truck.)

\section{Bad Cars or Bad Drivers?}

Our analyses show clearly enough that SUVs and trucks pose considerable dangers, but some of our other findings appear to have less to do with size, weight or design, and more to do with who tends to drive a particular vehicle and how. To probe these issues, we used information about age and gender, as well as various measures of illegal driving (alcohol or drug involvement, driving without a valid license or reckless driving in the crash, as well as the operator's driving record 
for the previous three years). And although we can only offer some suggestive observations rather than concrete conclusions, certain patterns seem clear enough to explain why one vehicle so often proves less dangerous than another.

For example, the safest vehicles (for the person sitting behind the steering wheel) are minivans; the riskiest are sports cars. Minivans have the lowest fraction of driver fatalities that are men under 26 years old (4 percent); sports cars have the highest (39 percent). So we suspect that differences in the behavior of their drivers account in large measure for why these two classes of vehicles pose such different risks to the people who operate them. After all, minivans are often used to transport children and, as a consequence, their drivers tend to be especially careful, whereas the people who zoom around in sports cars are likely to, well, cut corners in that regard. We found also that driving imported luxury cars carries extremely low risk, for reasons that are not obvious. Such cars typically have the newest safety technologies, so perhaps the presence of side-curtain airbags and electronic stability controls contributes here. But curiously, the relatively small number of driver fatalities arising from this class of automobile contains a sizable fraction of young men (21 percent). Assuming that this number just reflects the proportion of imported luxury cars driven by young men, we would conclude that vehicle design and safety features offset the risky nature of many of their drivers.

Smaller cars provide further evidence for this phenomenon. On average, the high-risk subcompact cars we identified appear to be driven by young men only slightly more frequently (23 percent) than are low-risk subcompact cars (21 percent), which suggests that factors other than the characteristics and behaviors of their drivers are causing the large difference in fatality rates. We believe that the details of the designs of these cars make them dangerous.

Another thing we learned was that the drivers killed in SUVs and pickups are no different, at least in terms of age, gender, and driving history, from those of most cars. Therefore, the comparatively high rollover risk and the risk to others we found for SUVs are probably not caused by the behavior of their operators. But we hesitate to ascribe the increased risks in pickups entirely to their design. Why not? Because pickups tend to be driven on rural roads to a greater extent than are cars and SUVs, and such roads are particularly dangerous, for a variety of reasons: They are often designed for lower speeds, but speed limits are rarely enforced; oncoming traffic is not typically separated by a barrier; shoulders rarely have guardrails, are usually narrow and sometimes don't exist at all; these roads are not as well lit; they are often far from trauma centers; and so forth.

To test whether these factors are truly at play, we calculated the population density of the county in which each crash took place. As expected, pickup fatalities occur, on average, in much more rural areas than do the deaths in cars or SUVs. An analysis we did of traffic-accident data from California by county also indicates that, for all vehicle types, fatality risks both to drivers and to drivers of other vehicles increase as population density decreases. Therefore, some of the high risk to others that we calculate for pickups comes from their traveling much of the time on dangerous rural roads, rather than purely from the aggressivity of their design.

To take things one step further, we also calculated risks for individual makes and models (Figure 4). And here we found some very interesting results. For instance, the lowest risk subcompact 
car, the VW Jetta, appears often to be driven by the most risk-prone drivers: 32 percent of them are young males, many with poor driving histories. Another telling example is the Hyundai Elantra. It had side-curtain airbags added for model year 2001, and we see a 30-percent reduction in risk to Elantra drivers after its redesign, which coincided with an improvement in its frontal crash-test rating, from 3 to 5 stars. Similarly, the Ford Focus has a nearly 40-percent lower risk to its drivers than the model it replaced, the Escort. Because the average driver of these models likely did not change much in such a short time period, these reductions suggest that vehicle design can indeed have a large effect on safety.

Figure 4. Analysis of a federal crash database illuminates the fatality risk associated with particular makes and models of cars and trucks - and apportions the overall risk between the driver of the vehicle in question (horizontal axis) and the drivers of any other vehicles involved in the crash (vertical axis). Half- and one-ton pickup trucks, which pose considerably higher risk to others than the models shown here, are omitted. (Differences of less than 20 percent are not statistically significant.)

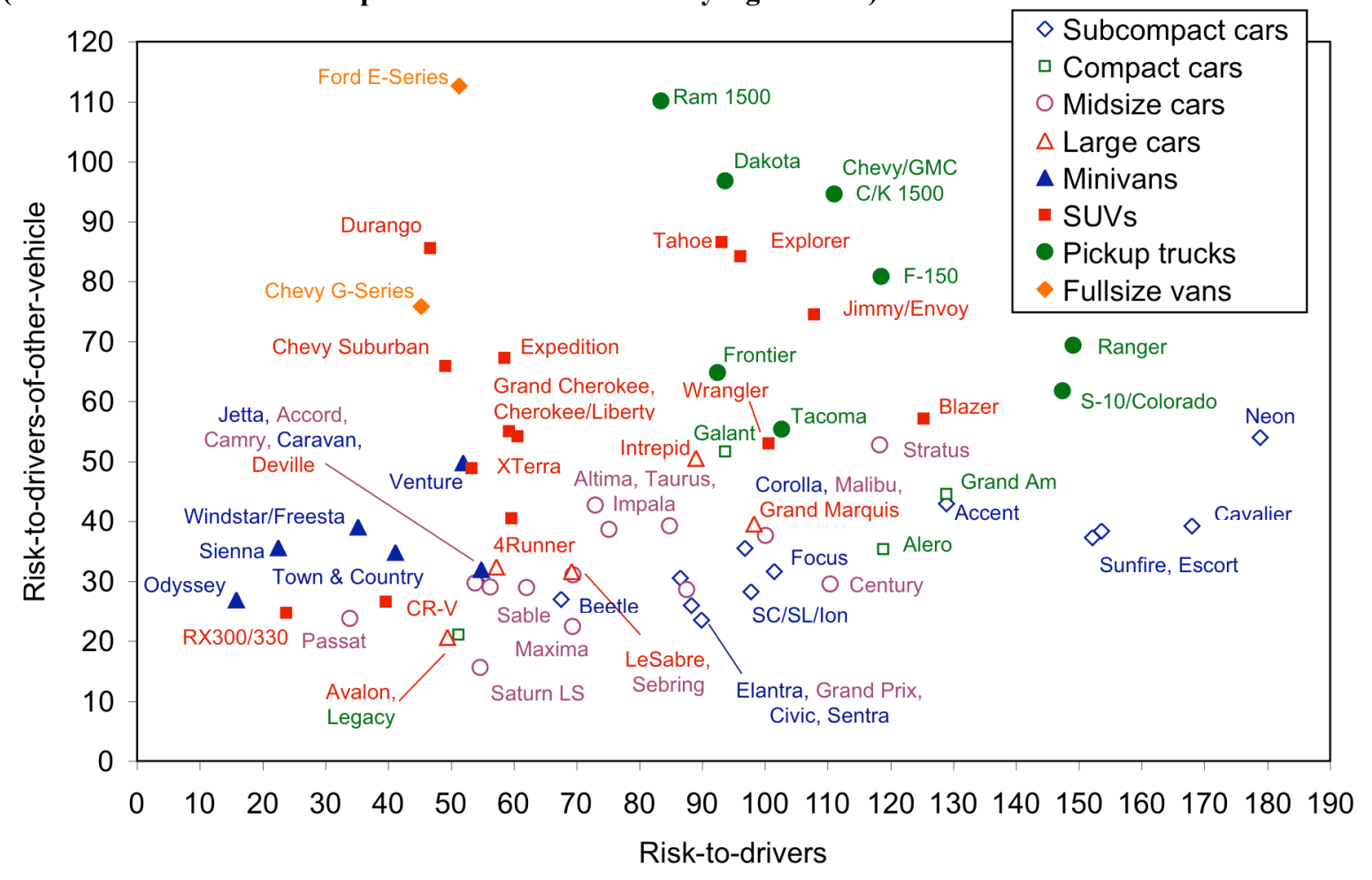

So how does the fatality risk of car models correlate with their masses? Not as well as one might be led to believe. Other attributes, such as vehicle make, correlate more strongly with fatality risk. In particular, Japanese and German cars have better safety records than U.S. or Korean cars of similar weight (Figure 5). And a car's resale value after five years of ownership is much more strongly correlated with reduced fatality risk than is mass. This observation provides yet more evidence that smart (dare we say "intelligent") design can overcome any disadvantage that lower mass may impart in certain types of crashes. 
Figure 5. Intriguing evidence already exists that safety is not inexorably tied to vehicle weight. In fact, the overall correlation between risk and weight (left) is quite weak, and focus on it misses the stronger dependence of risk on the vehicle's manufacturer: The products of Japanese and German makers (blue) have proven to be less risky than those of the U.S. "big three" (General Motors, Ford, and Chrysler, green)across a range of weights. Indeed, the tightest link appears to be with the resale price of the vehicle after five years (right), the more expensive vehicles proving the least risky.
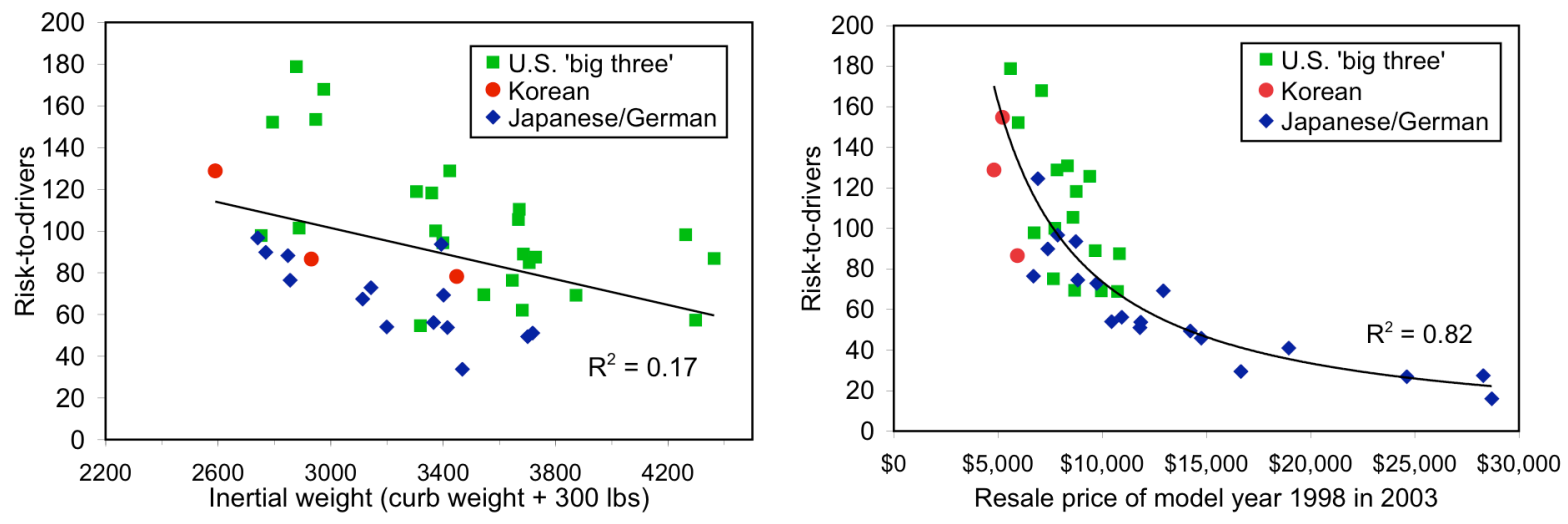

\section{What Then Must We Do?}

For too long the conventional wisdom that lighter cars and trucks are less safe has helped stymie efforts to increase the fuel economy of new vehicles and to reduce their greenhouse-gas emissions. This is a shame. One reason is that automotive engineers can improve fuel economy with no or little reduction in vehicle mass. Another is that with thoughtful design, lighter and smaller models can be made just as safe as larger, heavier ones, allowing even greater fuel economy.

The NHTSA recently issued rules modestly tightening fuel-economy standards for light-duty trucks, increasing the requirement for this category (which includes SUVs and minivans) from 22.2 miles per gallon to 23.5 miles per gallon by 2010. But the U.S. Court of Appeals overturned that measure in November 2007, telling the NHTSA, in essence, to do better. The scheme that the judges shot down continued to allow trucks to have lower fuel economy than cars; the NHTSA proposal also allowed larger trucks (defined by their "footprint") to have poorer fuel economy than smaller trucks. This size-based standard was preferable to a weight-based one that some were proposing, but it was still lacking, for many reasons.

The NHTSA adopted a size-based standard for trucks because regulators are clinging to the myth that smaller trucks are intrinsically less safe than larger ones. We and others have shown that this belief is unfounded: The center of gravity (in rollovers) and frontal height and stiffness (in crashes with objects), not footprint, are the important variables controlling protection of a vehicle's occupants. What's more, our analysis shows that larger pickups (as measured by their rated capacity) impose greater risk on the occupants of other vehicles than do smaller pickups.

So the NHTSA's size-based standard is not necessary to protect truck drivers. Worse, it jeopardizes car drivers. And the size-based standard fails to set any overall requirement for a manufacturer's fleet of light trucks. So by shifting production toward larger models, an automaker could in effect relax the fuel-economy requirements under which it operated. Clearly, 
such toothless measures will not provide the dramatic reductions in carbon dioxide emissions needed to combat global warming, nor will they put a dent into the problem of excessive dependence on foreign oil.

As the agency responsible for regulating both fuel economy and safety, the NHTSA can and should do better. The NHTSA should not try to regulate safety through the backdoor, by manipulating fuel-economy standards in such a way as to promote the sale of vehicles that some people believe might be less dangerous to their drivers by virtue of their great size and weight. Rather, the NHTSA should set fuel-economy standards independently from safety standards. For the latter, the nation clearly needs rules that take into account not just the dangers to a vehicle's occupants, but also the risk that a car or truck poses to others on the road.

The 2008 Energy Bill the president recently signed requires that new cars and light trucks have an average fuel-economy of 35 miles per gallon by 2020. Although this legislation does not explicitly call for a size-based standard, it still allows separate fuel economy levels for cars and trucks. By continuing to treat cars and light trucks differently, the provisions of the new law, as well as current safety standards, encourage consumers to purchase gas-guzzling and aggressive pickups and SUVs. Steps should be taken to apply the same standards equally to all light vehicles.

Requiring that all light-duty vehicles meet the same stringent fuel-economy standards would increase the manufacturing costs of large pickup trucks and SUVs substantially. But some sticker shock here would be beneficial, because it would discourage consumers from purchasing a big vehicle unless they really needed one. Those people who truly require a large truck, say to pull a trailer or to haul cargo for a business, could be helped by offering them appropriate tax incentives (as are available now for vehicles weighing more than 6,000 pounds). So large pickup trucks and enormous SUVs would still be around, but over time they would presumably be found in dwindling numbers.

That change alone would improve highway safety for society as a whole. Other gains would come from appropriate regulations on vehicle compatibility and aggressivity, tougher roof-crush standards and improved seat-belt technology, which together would save far more lives than might possibly be put in jeopardy by tightened fuel-economy standards. There's really no reason to think that you can't save people and the planet at the same time.

\section{References}

Heavenrich, R. 2005. Light-Duty Automotive Technology and Fuel Economy Trends: 1975 Through 2005. EPA 420-S-05-0001. U.S. Environmental Protection Agency, Washington, D.C.

Ross, M., D. Patel and T. Wenzel. 2006. "Vehicle design and the physics of traffic stafety." Physics Today 59:49-54.

Wenzel, T.P. and M. Ross. 2005. "The effects of vehicle model and driver behavior on risk." Accident Analysis and Prevention 37:479-494. 